\title{
EVALUASI PELATIHAN JARAK JAUH PENYULUH PAJAK MENGGUNAKAN MODEL KIRKPATRICK DAN IMPORTANCE PERFORMANCE ANALYSIS
}

\author{
Agus Suharsono $^{1}$, Oscar Wibiyakto ${ }^{2}$ \\ Balai Diklat Keuangan Yogyakarta, BPPK, Kementerian Keuangan ${ }^{1,2}$ \\ Email: gusharpramudito@gmail.com
}

\begin{abstract}
Abstrak
Pelatihan Jarak Jauh Penyuluh Pajak Dasar adalah pelatihan sebagai syarat untuk dapat diangkat sebagai Pejabat Fungsional Penyuluh Pajak pada Direktorat Jenderal Pajak, yang merupakan jabatan fungsional baru, demikian juga pelaksanaan pelatihannya juga baru pertamakalinya, dan dilaksanakan secara jarak jauh karena pandemi Covid-19 belum selesai. Metode yang digunakan adalah evaluasi model Kirkpatrick level-1 dan Importance Performance Analysis. Hasil evaluasi level-1 terhadap penyelenggaraan, semua unsur yang dievaluasi berada dalam kuadran I, artinya bagus dan perlu dipertahankan. Terdapat masukan yang perlu dipertimbangkan dalam pelaksanaan pelatihan berikutnya yaitu perlunya ditambah video pembelajaran tentang komunikasi yang baik, perlu ada pelatihan aplikasi yang digunakan dalam pembelajaran, mengurangi tatap muka melalui zoom, dan pengurangan jam belajar mandiri di malam hari. Evaluasi level-1 terhadap pengajar, semua unsur evaluasi masuk kuadran I, artinya bagus dan perlu dipertahankan. Saat ini pejabat yang diundang untuk memberikan ceramah dievaluasi dengan instrumen sama dengan pengajar. Disarankan pejabat yang memberikan ceramah tidak dievaluasi seperti pengajar, karena pejabat tersebut diundang untuk ceramah sesuai otoritas jabatannya, bukan pengajar tapi narasumber. Evaluasi level-2 sangat baik karena 96\% peserta lulus dengan predikat sangat baik.
\end{abstract}

Kata Kunci : Pelatihan Jarak Jauh, Penyuluh Pajak, Kirkpatrick, Analisis Kinerja Penting

\begin{abstract}
Basic Tax Extension Remote Training is a mandatory training to be appointed as a Tax Extension Functional Officer at the Directorate General of Taxes, which is a new functional position, the implementation of the training is also the first time conducted, and is carried out remotely due to the Covid-19 pandemic. The method used was the Kirkpatrick level-1 evaluation model and Importance Performance Analysis. The results of the level-1 evaluation of the implementation, all the elements evaluated were in quadrant I, meaning good and needed to be maintained. There were inputs to be considered in the implementation of the next training, namely the need to add learning videos on good communication, the need of application used in learning, reducing face-to-face meetings through zoom, and reducing hours of individual study in the evening. In Level-1 evaluation of the teachers, all elements of evaluation were included in quadrant I, meaning good and needed to be maintained. Currently, officials invited to give lectures are evaluated with the same instruments as the teachers. It is recommended that officials who give lectures are not evaluated as the teachers, because these officials are invited to lecture according to the authority of their position, not as teachers but as sources. Level-2 evaluation is very good because $96 \%$ of the participants passed with an excellent predicate.
\end{abstract}

Key Words : Distance Training, Tax Instructor, Kirkpatrick Evaluation Model, Importance Performance Analysis

\section{PENDAHULUAN}

Terdapat jabatan baru bagi Pegawai Direktorat Jenderal Pajak (DJP) yaitu Fungsional Penyuluh Pajak berdasarkan Permen PAN \& RB Nomor 49 Tahun 2020 Tentang Jabatan Fungsional Penyuluh
Pajak. Tujuan penetapan jabatan Fungsional Penyuluh Pajak adalah guna pengembangan karier dan peningkatan profesionalisme Pegawai Negeri Sipil (PNS) yang mempunyai ruang lingkup, tugas, tanggung jawab, dan wewenang 
dalam melaksanakan tugas penyuluhan di bidang perpajakan, serta untuk meningkatkan kinerja organisasi.

Penyuluhan Perpajakan adalah suatu upaya dan proses pemberian informasi perpajakan kepada masyarakat, dunia usaha, dan lembaga pemerintah maupun nonpemerintah. PNS yang menduduki Jabatan Fungsional Penyuluh Pajak harus memenuhi Standar Kompetensi sesuai dengan jenjang jabatan yang meliputi kompetensi teknis, kompetensi manajerial, dan kompetensi sosial kultural.

Guna meningkatkan pengetahuan dan ketrampilan calon Fungsional Penyuluh Pajak, Pusdiklat Pajak bekerjasama dengan Direktorat Penyuluhan, Pelayanan, dan Hubungan Masyarakat Direktorat Jenderal Pajak menyusun kurikulum dan kerangka acuan progran Pelatihan Jarak Jauh (PJJ) Fungsional Penyuluh Pajak Dasar. PJJ Fungsional Penyuluh Pajak merupakan syarat agar PNS DJP dapat diangkat menjadi Pejabat Fungsional Penyuluh Pajak, selain itu PPJ tersebut dilaksanakan pertamakali sesuai kebiasaan baru di masa pandemic Covid-19. Sehingga menarik untuk dilakukan evaluasi. PJJ menggunakan aplikasi zoom mendorong peserta untuk mempraktikkan secara langsung alat PJJ sehingga dapat mempermudah penyerapan materi pelatihan dan berhasil mencapai tujuan pelatihan dalam mengelola PJJ [1]. Implementasi e-learning cukup efektif meningkatkan pemahaman peserta terhadap mata pelatihan, namun perlu ditingkatkan agar dapat efektif menjadi blended learning, meliputi pembenahan aplikasi, fasilitator, waktu pelaksanaan, dan perlunya adaptasi unsur-unsur pembelajaran konvensional [2].

Evaluasi digunakan untuk mengetahui hasil belajar sesuai dengan tujuan pembelajaran [3], dan sangat penting untuk mengetahui efektifitas pembelajaran [4]. Peraturan Kepala BPPK Nomor PER5/PP/2017 Tentang Pedoman Evaluasi Pembelajaran Di Lingkungan Kementerian Keuangan mengatur bahwa evaluasi pelatihan menggunakan model evaluasi Kirkpatrick dan Importance Performance Analysis, adapun manfaat adalah untuk pengambilan keputusan kelulusan, bahan perencanaan dan masukan perbaikan.

Evaluasi model Kirkpatrick terdapat empat level, yaitu: 1) Level-1: Reaction untuk mengukur kepuasan peserta; 2) Level-2: Learning untuk mengukur proses pembelajaran; 3) Level-3: Behavior bertujuan mengetahui penerapan dalam pekerjaan; dan 4) Level-4: Results hasil akhir setelah pembelajaran [5].

Penelitian terdahulu menunjukkan bahwa Evaluasi Model Kirkpatrick pada Latsar CPNS mampu membuat peserta dapat mengaplikasikan konsep-konsep pada mata pelatihan, dalam proses pembelajaran dibutuhkan fasilitator yang mempunyai kemampuan mengajar dengan baik, dan juga mampu melakukan evaluasi yang efektif [6]. Evaluasi Diklat ASN Model Kirkpatrick (Studi Kasus Pelatihan Effective Negotiation Skill Balai Diklat Keuangan Makassar) diketahui bahwa keseluruhan aspek evaluasi penyelenggaraan dinilai Sangat Baik, dan evaluasi pengajar telah dapat memenuhi harapan dari peserta dengan kategori Sangat Baik [8]. Evaluasi Kirkpatrick akan efektif jika dirumuskan secara operasional sesuai dengan kebutuhan instrumen penelitian, dan menggunakan teknologi informasi komunikasi berbasis online [9].

Keberhasilan pelatihan juga ditentukan oleh Kepuasan peserta dianalis menggunakan empat kuadran Importance Performance Analysis, menurut John A. Martilla and John C. James sebagai berikut: 1) tentukan atribut yang akan diukur; 2) pisahkan ukuran kepentingan 
dan ukuran kinerja; 3) posisikan sumbu vertikal dan horizontal; 4) tentukan nilai median sebagai ukuran sentral; 5) analisis hasil kinerja-kepentingan secara sistematis; dan 6) susun strategi berdasarkan hasil analisis [10]. Metode mengukur kinerja menggunakan Important Performance Analysis perlu ditambah menjadi Modified Importance Performance Analysis yaitu dengan membandingkan entitas yang lain [11]. Uji coba beberapa pendekatan untuk melakukan Importance Performance Analysis diketahui bahwa pendekatan grid $2 \times 2$ tradisional dan regresi berganda dapat menyesatkan, metode yang paling valid adalah dengan mengidentifikasi dan konfirmasi validitas instrumennya [12].

\section{METODE}

Rancangan penelitian ini menggunakan evaluasi pelatihan model Kirkpatrick Level-1: Reaction untuk mengukur kepuasan peserta yang dianalisis menggunakan kuadran Importance Performance Analysis, dan Level-2: Learning untuk mengukur proses belajar dalam. Sasaran evaluasi adalah PJJ Fungsional Penyuluh Pajak Dasar Angkatan I TA 2021 tanggal 25 Januari dan 01 Februari 2021 yang dilaksanakan di Balai Diklat Keuangan Yogyakarta. Instrumen pengumpulan data yang digunakan adalah adalah instrumen yang diatur dalam Peraturan Kepala BPPK Nomor PER-5/PP/2017. Data dikumpulkan secara online dan tatap muka, instrumen yang digunakan adalah Formulir Evaluasi Penyelenggaraan Program E-Leaming yang diisi secara online yang hasilnya ditabulasikan berdasarkan kepentingan dan harapan. Kuesioner menggunakan skala Likert dengan skala penilaian harapan adalah: 1: Tidak Penting; 2: Kurang Penting; 3: Cukup Penting; 4: Penting; dan 5: Sangat Penting, sedangkan skala penilaian kenyataan adalah: 1: Tidak Baik; 2: Kurang Baik; 3: Cukup Baik; 4: Baik; dan 5: Sangat Baik. Selain itu dalam kuesioner juga disediakan jawaban terbuka. Jawaban kuesioner kemudian dilakukan tabulasi untuk dianalisis menggunakan kuadran Importance Performance Analysis. Untuk memperdalan hasil evaluasi melalui kuesioner, pengambilan data juga dilakukan secara tatap muka diakhir pelatihan. Data yang terkumpul dianalisis secara logiko-induktif yaitu proses berpikir yang menggunakan logika untuk memahami pola dan kecenderungan dalam data melalui tiga tahap yaitu pengkodean, mendeskripsikan karakteristik utama, dan menginterpretasikan data [13]. Hasil analisis data disajikan secara kualitatifdeskriptif.

\section{HASIL DAN PEMBAHASAN Profil Peserta Pelatihan}

Profil peserta pelatihan berdasarkan usia, jenis kelamin, dan jabatan adalah sebagaimana Tabel 1.

Tabel 1. Profil Peserta Pelatihan Berdasarkan Usia, Jenis Kelamin, dan Jabatan

\begin{tabular}{|c|c|c|c|}
\hline \multirow{2}{*}{$\begin{array}{l}\text { No } \\
\text { A. } \\
\end{array}$} & \multirow[t]{2}{*}{ Uraian } & \multicolumn{2}{|c|}{ Jumlah } \\
\hline & & & \\
\hline 1 & $30-35$ & 8 & $29 \%$ \\
\hline 2 & $36-40$ & 6 & $21 \%$ \\
\hline 3 & $41-45$ & 5 & $18 \%$ \\
\hline 4 & $46-50$ & 6 & $21 \%$ \\
\hline 5 & $51-55$ & 2 & $7 \%$ \\
\hline 6 & $56-60$ & 1 & $4 \%$ \\
\hline & Jumlah & 28 & $100 \%$ \\
\hline B. & Jenis Kelamin & & \\
\hline 1 & Perempuan & 16 & $57 \%$ \\
\hline 2 & Laki-Laki & 12 & $43 \%$ \\
\hline & Jumlah & 28 & $100 \%$ \\
\hline C. & Jabatan & & \\
\hline 1 & Account Representative & 19 & $68 \%$ \\
\hline 2 & Pelaksana & 7 & $25 \%$ \\
\hline 3 & Juru Sita & 1 & $4 \%$ \\
\hline 4 & Kepala Seksi & 1 & $4 \%$ \\
\hline & Jumlah & 28 & $100 \%$ \\
\hline
\end{tabular}

Sebaran tempat peserta pelatihan mengikuti pelatihan tersebar di wilayah sebagai berikut: 1) D.I Yogyakarta: Bantul 1 orang; 2) DKI Jakarta: Jakarta 1 orang; 
dan 3) Jawa Tengah: Semarang 5 orang, Demak 2 orang, Semarang 2 orang, Karanganyar 2 orang, Purwokerto 2 orang, Sukoharjo 2 orang, dan masing-masing 1 orang di Batang, Boyolali, Jepara, Kebumen, Klaten, Kudus, Magelang, Pekalongan, Purbalingga, Salatiga, Surakarta. Dominasi sebaran peserta adalah Jawa Tengah, kemudian D.I Yogyakarta dan DKI Jakarta. PJJ memungkinkan diikuti peserta dari berbagai daerah tanpa meninggalkan kota tempat tinggal karena pelatihan diadakan pada saat pandemi Covid-19.

\section{Evaluasi Level-1: Penyelenggaraan Pelatihan}

Hasil analisis berdasarkan kuesioner delapan pertanyaan harapan dan kenyataan terhadap penyelenggaraan pelatihan adalah sebagaimana Tabel 2 .

Tabel 2 Ananlisis Gab Antara Harapan dan Kenyataan terhadap Penyelenggaraan Pelatihan

\begin{tabular}{|c|c|c|c|}
\hline No & Butir & $\begin{array}{c}\text { Hara } \\
\text { pan }\end{array}$ & $\begin{array}{c}\text { Kenya } \\
\text { taan }\end{array}$ \\
\hline 1 & $\begin{array}{l}\text { Kesesuaian materi } \\
\text { pembelajaran dengan } \\
\text { harapan peserta }\end{array}$ & 4,64 & 4,93 \\
\hline 2 & $\begin{array}{l}\text { Bahan ajar mudah } \\
\text { dipahami }\end{array}$ & 4,64 & 4,89 \\
\hline 3 & $\begin{array}{l}\text { Kesesuaian metode } \\
\text { pembelajaran dengan } \\
\text { materi PJJ }\end{array}$ & 4,61 & 4,79 \\
\hline 4 & $\begin{array}{l}\text { Ketercukupan waktu } \\
\text { penyelenggaraan PJJ } \\
\text { dengan jumlah materi } \\
\text { yang diberikan }\end{array}$ & 4,57 & 4,71 \\
\hline 5 & $\begin{array}{l}\text { Kesigapan } \\
\text { penyelenggara dalam } \\
\text { melayani peserta } \\
\text { selama proses PJJ }\end{array}$ & 4,61 & 4,86 \\
\hline 6 & $\begin{array}{l}\text { Ketercukupan waktu } \\
\text { dalam mengerjakan } \\
\text { penugasan, kuis atau } \\
\text { ujian }\end{array}$ & 4,57 & 4,68 \\
\hline 7 & $\begin{array}{l}\text { Fasilitas PJJ mudah } \\
\text { diakses }\end{array}$ & 4,61 & 4,75 \\
\hline 8 & $\begin{array}{l}\text { Fasilitas PJJ mudah } \\
\text { digunakan }\end{array}$ & 4,61 & 4,75 \\
\hline & Rata-Rata & 4,61 & 4,79 \\
\hline
\end{tabular}

Berdasarkan Tabel 2 diketahui gab tertinggi adalah pada butir kesesuaian materi pembelajaran dengan harapan peserta sebesar 0,29; secara berurutan kemudian bahan ajar mudah dipahami sebesar 0,25; kesigapan penyelenggaraan PJJ dengan jumlah materi yang diberikan sebesar 0,25; Kesesuaian metode pembelajaran dengan materi PJJ sebesar 0,18; Ketercukupan waktu penyelenggaraan PJJ dengan jumlah materi yang diberikan, Fasilitas PJJ mudah diakses, Fasilitas PJJ mudah digunakan masing-masing dengan nilai sama yaitu sebesar 0,14; dan butir dengan gab paling kecil adalah Ketercukupan waktu dalam mengerjakan penugasan, kuis atau ujian sebesar 0,11. Dari delapan butir evaluasi butir ketercukupan waktu dalam mengerjakan penugasan, kuis atau ujian harus menjadi bahan evaluasi perbaikan kurikulum pada pelatihan berikutnya.

Gab harapan dan kenyataan penyelenggaraan pelatihan menurut peserta adalah sebagaimana Gambar 11.

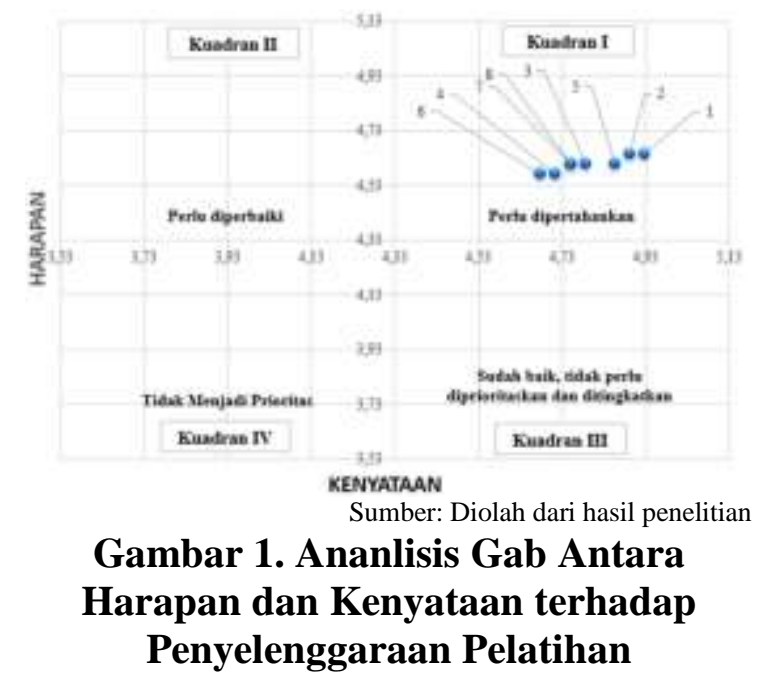

Berdasarkan Gambar 1, diketahui gab harapan dan kenyataan terhadap penyelenggaraan pelatihan meskipun nilainya beragam, namun semua butir evaluasi masuk dalam kuadran I yang artinya seluruh persepsi peserta pelatihan 
terhadap penyelenggaraan pelatihan adalah baik dan penyelenggara pelatihan diharapkan untuk selalu mempertahankan harapan dan kenyataan.

Untuk mengetahui lebih dalam persepsi peserta pelatihan terhadap penyelenggaraan pelatihan berdasarkan pengukuran berdasarkan kuesioner dengan skala Likert maka juga disediakan pertanyaan terbuka dan wawancara kelompok di kelas pada akhir pelatihan dengan hasil sebagaimana Tabel 3.

Tabel 3. Masukan Peserta terhadap Penyelenggaraan Pelatihan

\begin{tabular}{clcc}
\hline No & \multicolumn{1}{c}{ Uraian } & \multicolumn{2}{c}{ Jumlah } \\
\hline 1 & Sudah bagus & 10 & $33 \%$ \\
2 & Tidak ada & 6 & $20 \%$ \\
3 & Perlu ditingkatkan lagi & 3 & $10 \%$ \\
4 & Sebaiknya dikurangi & 3 & $10 \%$ \\
& pelajaran jam malam hari & & \\
5 & $\begin{array}{l}\text { Ditambahkan video contoh } \\
\text { komunikasi yang baik }\end{array}$ & 1 & $3 \%$ \\
6 & Materi dibuat lebih menarik & 1 & $3 \%$ \\
7 & $\begin{array}{l}\text { Materi sudah bagus } \\
8\end{array}$ & 1 & $3 \%$ \\
& $\begin{array}{l}\text { Materi terlalu banyak } \\
\text { sehingga waktunya kurang }\end{array}$ & 1 & $3 \%$ \\
9 & $\begin{array}{l}\text { Perlu pelatihan penggunaan } \\
\text { aplikasi pembelajaran }\end{array}$ & 1 & $3 \%$ \\
10 & $\begin{array}{l}\text { Perlu pengurangan waktu } \\
\text { tatap muka melalui zoom }\end{array}$ & 1 & $3 \%$ \\
11 & Semoga bisa ikut pelatihan & 1 & $3 \%$ \\
& lagi di BDK Yogyakarta & & \\
12 & Tergantung sinyal & 1 & $3 \%$ \\
\hline & Jumlah $\quad$ Sumber: Diolah dari hasil penelitian
\end{tabular}

Berdasarkan Tabel 3 diketahui meskipun berdasarkan Gambar 1 semua butir berada pada kuadran I yang artinya sudah baik dan perlu dipertahankan, namun masukan peserta perlu dipertimbangkan dalam upaya perbaikan penyelenggaraan pelatihan. Masukan yang perlu mendapat perhatian adalah perlunya ditambah video pembelajaran tentang komunikasi yang baik, perlu pelatihan aplikasi yang digunakan dalam pembelajaran yaitu zoom, padlet, quizizz, dan google spread sheet. Masukan tersebut perlu diperhatian pada pelatihan berikutnya, perlu ditanyakan kepada peserta sudah pernah menggunakan aplikasi yang akan digunakan selama pelatihan atau belum, jika belum maka dilakukan bimbingan singkat dan disediakan video tutorialnya.

Masukan terkait dengan adanya gangguan sinyal, berhubungan dengan masukan agar mengurangi tatap muka melalui zoom. Untuk itu harus ada solusi agar tidak terlalu lama menggunakan zoom secara synchrounus yang memerlukan sinyal kuat dan melelahkan. Altenatif yang dapat dilakukan adalah menggunakan media yang tidak, altenatif lain adalah dengan menambah penggunaan aplikasi pembelajaran synchrounus misalnya google spead sheet, google class room, atau YouTube.

Masukan sehubungan dengan perlunya pengurangan jam pelatihan malam hari. Pelatihan tersebut memang ada jadwal tugas mandiri pada malam hari. Jam kerja Pegawai Kementerian Keuangan adalah pukul 07.30-17.00. Sedangkan jadwal pelatihan adalah sebagaimana Tabel 4 .

Tabel 4 Masukan Peserta terhadap Penyelenggaraan Pelatihan

\begin{tabular}{ccc}
\hline Pelaksanaan & Tatap Muka & $\begin{array}{c}\text { Tugas } \\
\text { Mandiri }\end{array}$ \\
\hline Hari-1 & $08.00-17.45$ & $19.30-21.45$ \\
Hari-2 & $08.00-17.00$ & - \\
Hari-3 & $08.00-17.00$ & $19.30-21.45$ \\
Hari-4 & $08.00-17.45$ & $19.30-21.00$ \\
Hari-5 & $08.00-17.45$ & - \\
Hari-6 & $08.00-17.00$ & - \\
Hari-7 & $08.00-16.15$ & - \\
\hline \multicolumn{3}{c}{ Sumber: Diolah dari hasil penelitian }
\end{tabular}

Berdasarkan Tabel 4 diketahui bahwa jadwal tatap muka pelatihan ini sudah sesuai dengan jam kerja Pegawai Kementerian Keuangan. Dari tujuh hari pelatihan terdapat tiga hari tugas mandiri di malam hari selama dua jam seperempat dan satu jam empat puluh lima menit. Sebenarnya pelatihan ini ada tugas membuat bahan tayang yang akan digunakan dalam ujina akhir yang tidak 
cukup dikerjakan paja jam tugas mandiri yang dijadwalkan, artinya hampir tiap malam peserta masih mengerjakan tugas. Mengingat usia peserta yang beragam dan tugas yang harus dikerjakan sebaiknya dilakukan evaluasi jumlah jam pelatihan malam hari. Salah satu altenatifnya adalah tugas mandiri dikerjakan secara asynchrounus sebalum pelatihan tatap muka secara jarak jauh dilaksanakan secara synchrounus.

\section{Evaluasi Level-1: Pengajar Pelatihan}

Hasil analisis berdasarkan kuesioner delapan pertanyaan harapan dan kenyataan terhadap pengajar adalah sebagaimana Tabel 5.

\begin{tabular}{|c|c|c|}
\hline Pengajar Mata Pelalihan & $\begin{array}{c}\text { Hara } \\
\text { pan }\end{array}$ & $\begin{array}{c}\text { Kenya } \\
\text { Taan }\end{array}$ \\
\hline $\begin{array}{l}\text { Ceramah I: Kebijakan Terkini } \\
\text { terkait Penyuluhan }\end{array}$ & 4,57 & 4,79 \\
\hline $\begin{array}{l}\text { Manajemen Pelaksanaan } \\
\text { Kegiatan Penyuluhan } \\
\text { Perpajakan }\end{array}$ & 4,54 & 4,96 \\
\hline $\begin{array}{l}\text { Administrasi Layanan } \\
\text { Perpajakan }\end{array}$ & 4,54 & 4,93 \\
\hline $\begin{array}{l}\text { Metode dan Teknik } \\
\text { Penyuluhan Perpajakan }\end{array}$ & 4,54 & 4,96 \\
\hline Kemampuan Komunikasi & 4,54 & 4,96 \\
\hline $\begin{array}{l}\text { Ceramah II: Sistem } \\
\text { Administrasi dan Ketentuan } \\
\text { Angka Kredit bagi Fungsional } \\
\text { Penyuluh Pajak }\end{array}$ & 4,57 & 4,82 \\
\hline $\begin{array}{l}\text { Pengantar Manajemen Contact } \\
\text { Center }\end{array}$ & 4,54 & 4,89 \\
\hline Rata-Rata & 4,54 & 4,92 \\
\hline
\end{tabular}

Berdasarkan Tabel 5 diketahui gab tertinggi antara harapan dan kenyataan terhadap pengajar pelatihan sebesar 0,43 ada pada tiga mata diklat yaitu: Manajemen Pelaksanaan Kegiatan Penyuluhan Perpajakan, Metode dan Teknik Penyuluhan Perpajakan, dan Kemampuan Komunikasi. Berikutnya adalah mata pelatihan Administrasi Layanan Perpajakan sebesar 0,39;
Pengantar Manajemen Contact Center sebesar 0,36. Terdapat dua materi ceramah dengan gab harapan dan kenyataan rendah yaitu Ceramah I: Kebijakan Terkini terkait Penyuluhan sebesar 0,21 dan Ceramah II: Sistem Administrasi dan Ketentuan Angka Kredit bagi Fungsional Penyuluh Pajak sebesar 0,25. Materi ceramah sebaiknya tidak dilakukan evaluasi, karena ceramah dilakukan oleh Pejabat minimal eselon III yang diundang karena jabatannya sesuai dengan materi ceramah, artinya bukan pengajar tetapi karena otoritasnya, lebih tepat jika disebut narasumber, sehingga tidak perlu dilakukan evaluasi pengajar pelatihan. Jika peserta memberi nilai tidak terlalu tinggi kepada pejabat yang memberikan ceramah dapat dipahami, karena pejabat diundang untuk ceramah bukan untuk mengajar. Jika harus dievaluasi pun tidak dengan instrument yang sama dengan evaluasi pengajar, harus dibuat instrument khusus, misalnya kebaruan isi ceramah dan hubungan isi ceramah dengan tujuan pembelajaran.

Gab harapan dan kenyataan terhadap pengajar menurut peserta adalah sebagaimana Sumber: Diolah dari hasil penelitian

\section{Gambar 2.}

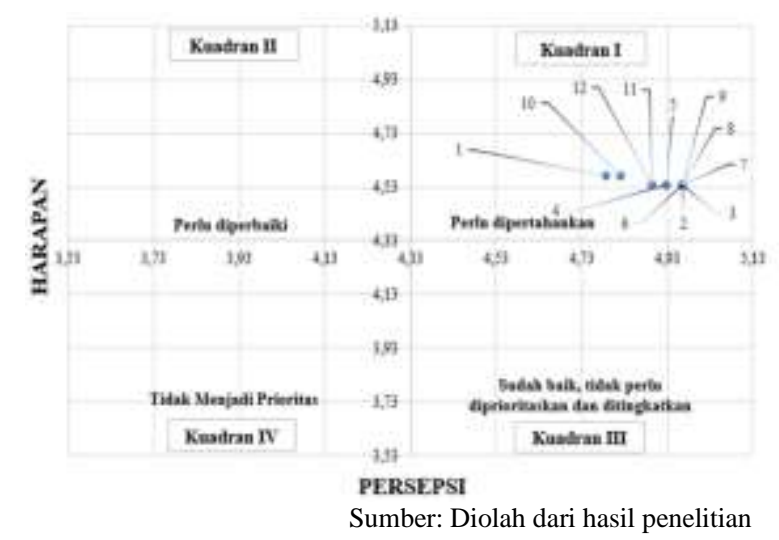

$$
\begin{gathered}
\text { Gambar } 2 \text { Ananlisis Gab Antara } \\
\text { Harapan dan Kenyataan terhadap } \\
\text { Pengajar Pelatihan }
\end{gathered}
$$

Berdasarkan Sumber: Diolah dari hasil penelitian 
Gambar 2 diketahui gab harapan dan kenyataan terhadap pengajar pelatihan meskipun nilainya beragam, namun semua butir evaluasi masuk dalam kuadran I yang artinya seluruh persepsi peserta pelatihan terhadap pengajar pelatihan adalah baik dan pengajar pelatihan diharapkan untuk selalu mempertahankan harapan dan kenyataan.

Untuk mengetahui lebih dalam persepsi peserta pelatihan terhadap pengajar pelatihan berdasarkan pengukuran berdasarkan kuesioner dengan skala Likert maka juga disediakan pertanyaan terbuka dan wawancara kelompok di kelas pada akhir pelatihan dengan hasil sebagaimana Tabel 6.

Tabel 6 Masukan Peserta terhadap Pengajar Pelatihan

\begin{tabular}{|c|c|c|c|}
\hline No & Uraian & \multicolumn{2}{|c|}{ Jumlah } \\
\hline 1 & Pengajarnya sudah bagus & 18 & $62 \%$ \\
\hline 2 & $\begin{array}{l}\text { Kelasnya interaktif dan } \\
\text { menyenangkan }\end{array}$ & 8 & $28 \%$ \\
\hline 3 & Sebaiknya tatap muka & 2 & $7 \%$ \\
\hline 4 & Pelatihannya step by step & 1 & $3 \%$ \\
\hline & Jumlah & 29 & $100 \%$ \\
\hline
\end{tabular}

Berdasarkan Tabel 6 diketahui bahwa semua masukan kepada pangajar pelatihan cukup bagus. PJJ secara online menuntut kreatifitas pengajar agar peserta bisa mengikuti, salah satunya metodenya dibuat step by step dan menggunakan media yang dapat digunakan diskusi online yaitu google spread sheet, dan padlet sebagai variasi tatap muka melali zoom. Masukan agar ada pelatihan tatap muka belum bisa dipenuhi karena pandemi Covid-19 belum usai.

\section{Evaluasi Level-2: Hasil Pelatihan}

Evaluasi level-2 dihitung dari hasil nilai akhir pelatihan untuk mengukur mengukur proses belajar dalam pembelajaran atau transfer of learning dihitung dengan bobot $40 \%$ dari nilai aktivitas selama mengikuti pelatihan dan $60 \%$ dari nilai ujian akhir. Penilaian peserta pelatihan terhadap penyelenggaraan pelatihan baik juga berpengaruh terhadap hasil pelatihan. Evaluasi level-2, dari 28 peserta, 27 orang atau $96 \%$ lulus dengan predikat amat baik, dan 1 orang atau $4 \%$ lulus dengan predikat baik.

\section{SIMPULAN}

Evaluasi level-1 terhadap penyelenggaraan pelatihan diketahui bahwa semua unsur yang dievaluasi berada dalam kuadran I, artinya bagus dan perlu dipertahankan. Masukan yang penting untuk dipertimbangkan adalah perlunya ditambah video pembelajaran tentang komunikasi yang baik, perlu ada pelatihan aplikasi yang digunakan dalam pembelajaran, mengurangi tatap muka melalui zoom, dan pengurangan jam belajar mandiri di malam hari. Evaluasi level-1 terhadap pengajar pelatihan juga bagus, semua unsur evaluasi masuk kuadran I, artinya bagus dan perlu dipertahankan. Saat ini pejabat yang diundang untuk memberikan ceramah juga dilakukan evaluasi dengan instrumen yang sama dengan pengajar. Disarankan pejabat yang memberikan ceramah tidak dievaluasi seperti pengajar, karena pejabat tersebut diundang untuk ceramah sesuai otoritas jabatannya, bukan pengajar tapi narasumber. Hasil evaluasi penyelenggaraan pelatihan yang bagus menghasilkan lulusan yang bagus karena 96\% peserta lulus dengan predikat sangat baik, $4 \%$ lulus dengan predikat baik.

\section{DAFTAR PUSTAKA}

[1] F. S. N. D. A. W. H. S. Y. Ariadhy, "Permasalahan Pembelajaran Jarak Jauh di Era Pandemi," Anoa J. Pengabdi. Masy., vol. 1, no. 3, pp. 13-18, 2020.

[2] M. A. R. R. A. K. Hidayah, "Evaluasi Penerapan Model Pembelajaran E-Learning pada Pelatihan Dasar Calon Pegawai Negeri Sipil," J. Borneo Adm., vol. 16, no. 1, pp. 101-116, 2020, doi: 
10.24258/jba.v16i1.656.

[3] I. Magdalena, H. N. Fauzi, R. Putri, dan U. M. Tangerang, "Pentingnya Evaluasi dalam Pembelajaran dan Akibat Memanipulasinya," vol. 2, pp. 244-257, 2020.

[4] K. H. Primayana, S. Tinggi, A. Hindu, N. Mpu, dan K. Singaraja, "Peran Desain Evaluasi Pembelajaran," vol. 4, no. 2, pp. 88 100, 2020.

[5] D. L. K. and J. D. Kirkpatrick, Evaluating Programs Training The Four Levels, Third Edit. 2011.

[6] R. Aulia, "Penerapan Model Evaluasi Kirkpatrick pada Pelatihan Dasar CPNS Calon Hakim MA pada Mata Pelatihan ANEKA di Balai Diklat Keagamaan Jakarta," Wawasan, vol. 1, no. 2, pp. 22-29, 2020.

[7] B. Subandriyo, "Pelatihan Ms Office Tingkat Lanjutan di Pusdiklat Sekretariat Jenderal dan Badan Keahlian Dewan Perwakilan Rakyat," Pancanaka, vol. 1, no. 2, pp. 89-96, 2020, doi: 10.37269/pancanaka.v1i2.49.

[8] A. Iskandar, "Evaluasi Diklat ASN Model Kirkpatrick (Studi Kasus Pelatihan Effective Negotiation Skill Balai Diklat Keuangan Makassar)," J. Pendidik., vol. 20, no. 1, p. 18, 2019 , doi: 10.33830/jp.v20i1.733.2019.

[9] T. Sopandi, "the Analysis of the Effectiveness of the Indonesian National Police'S Intelligence Specialized Developmental Education Using Kirkpatrick Training Evaluation Model," Int. Rev. Humanit. Stud., vol. 5, no. 1, pp. 77-92, 2020, doi: 10.7454/irhs.v0i0.220.

[10] J. A. Martilla and J. C. James, "Importance-performance analysis," J. Mark., vol. 41, no. 1, p. 77, 1986.

[11] E. D. B. Fitriaa, "Analisis Kualitas Pelayanan Mahasiswa Menggunakan
Modified Importance Performance Analysis," 2020.

[12] D. R. Bacon, "A comparison of approaches to ImportancePerformance Analysis," Int. J. Mark. Res., vol. 45, no. 1, pp. 1-15, 2003.

[13] Craig A. Mertler, Action Research, Improving Schools and Empowering Educators, Fifth Edit. California: SAGE Publications, 2017. 